\title{
Integrating 3D Game Engines in Enhancing Urban Perception: A Case Study of Students' Visualization of Urban Space
}

Rawan Abu Alatta ${ }^{1}$ | Hind Momani ${ }^{2}$

Received: 2020-11-27 | Final version: 2021-07-06

Abstract

\begin{abstract}
In urban design, consideration of urban participation, perception, and experience is very important for achievement of successful, easy-to-implement, and user-friendly spatial design. Participatory urban visualization is a method that allows residents to be involved in formulating the future of their locality. This paper reports a case study of participation of 15 volunteer students in visualization of the future of their locality via three methods: physical models, pre-rendered animated walkthrough, and an interactive real-time demo. The study examines the impact of using the three-dimension (3D) Unity game engine on urban space imageability and understanding. Accordingly, this paper presents a comparative study of the three visualization techniques by analyzing the results of a series of experiments, a questionnaire, and observations. The outcomes support that the used 3D game engine provides an efficient tool that can help users to experience, perceive, and understand urban solutions interactively and effectively. Furthermore, this study confirms the role of technology in enhancing the user's learning experience. Additionally, the study results indicate that integrating interactive game technology in urban space visualization has positive effect on space perception of people.
\end{abstract}

Keywords: Interactive 3D environment; game engines; 3D Unity; urban perception; students' involvement; urban space visualization

\section{Integración de motores de juegos 3D para mejorar la percepción urbana: caso de estudio de la visualización del espacio urbano por parte de estudiantes}

Abstract

\begin{abstract}
En el diseño urbano, la consideración de la participación, percepción y experiencia urbanas es muy importante para lograr un diseño espacial exitoso, fácil de implementar y amigable para el usuario. La visualización urbana participativa es un método que permite a los residentes involucrarse en la formulación del futuro de su localidad. Este documento informa un estudio de caso de participación de 15 estudiantes voluntarios en la visualización del futuro de su localidad a través de tres métodos: modelos físicos, recorrido animado pre-renderizado y una demostración interactiva en tiempo real. El estudio examina el impacto del uso del motor de juego Unity de tres dimensiones (3D) en la capacidad de imagen y comprensión del espacio urbano. En consecuencia, este artículo presenta un estudio comparativo de las tres técnicas de visualización mediante el análisis de los resultados de una serie de experimentos, un cuestionario y observaciones. Los resultados respaldan que el motor de juego 3D (Unity) utilizado proporciona una herramienta eficiente que puede ayudar a los usuarios a experimentar, percibir y comprender las soluciones urbanas de manera interactiva y eficaz. Además, este estudio confirma el papel de la tecnología en la mejora de la experiencia de aprendizaje del usuario. Además, los resultados del estudio indican que la integración de la tecnología de juegos interactivos en la visualización del espacio urbano tiene un efecto positivo en la percepción espacial de las personas.
\end{abstract}

Palabras clave: Entorno 3D interactivo; motores de juegos; Unidad 3D; percepción urbana; participación estudiantil; visualización del espacio urbano

${ }^{1}$ Full Time Lecturer, Al-Balqa’ Applied University (ORCiD: 0000-0002-5490-3892), ${ }^{2}$ Full Time Lecturer, Jordan University of Science and Technology (ORCiD: 0000-0003-0886-8800), Contact e-mail: rawanabualata@bau.edu.jo 


\section{Introduction}

Urban involvement is an essential part of urban design, which is a participatory process between urban designers, government, investors, stakeholders, and users (Wu, He, and Gong 2010). To this process, the designers contribute technical knowledge and skills whereas the citizens provide community history, knowledge, and values (Sameh 2011). The citizens work on handling their problems and cooperate in solving them (Fares, Taha, and Sayad 2018). Urban attachment with urban design meets citizens' values and needs according to their priorities. It also represents architectural, social, and economic aspects, where citizens play the role of decision makers for the city (Sameh 2011).

Kevin Lynch, Alexander Wallis, Claude Levi-Strauss, and Umberto Eco are urban planners and designers who believed in the necessity and importance of citizens' role in reshaping real spaces in cities (Sameh 2011). In 1960, Lynch highlighted how people perceived their surroundings and described images of an environment created by experiencing several elements, which have been later described as the five basic elements. These elements are paths, which are the routes through which people walk; edges, which are borders and breaks in continuity; districts, which are areas distinguished by common characteristics; nodes, which are strategic focal points for orientation; and external points of orientation called landmarks (Lynch 1984). Later, many urban planners incorporated Lynch's elements with urban design techniques to improve urban perception and participation in the mental image created (Meenar, Afzalan, and Hajrasouliha 2019). Creighton (2015) defined participation as "the process by which urban concerns, needs, and values are incorporated into governmental and corporate decision-making" (Creighton 2005). So, the locals are the stockholders who best know about the issues that affect them and their locality. Common objectives of involving citizens in local development are exchanging information, discovering common needs, resolving conflicts in design, and identifying the most accepted development scenarios (Sanoff 1999). This enhances creativity, generates innovative ideas, and ensures strong commitment of the citizens to the proposed or foreseen changes(Namdarian et al. 2021; Marszal et al. 2011).

\subsection{Technology and Urban Participation}

Urban participation in the design process faces many obstacles because of its dependence on conventional tools like storytelling, sketching, and drawing (Poplin, 2011). One of the biggest challenges is that many participants do not recognize the tools of the participation process as it takes place. This creates a gap between designers as decision makers and participants, which reduces effectiveness of the participation process (Fares, Taha, and Sayad 2018). This gap can be bridged by involving the citizens officially in the construction stages of any urban project so as to get a real understanding of their culture, needs, and behavior (Fares, Taha, and Sayad 2018).

Over the last century, technical inventions have progressively emerged as an essential factor in urban design in response to the need for better design skills to deal with cities in the urban realm. In addition, there is a need for urban designers and planners to communicate efficiently with citizens. Recently, technological innovations like the Geographic Information System (GIS), computer-aided design (CAD), Building Information Modeling (BIM), Virtual Reality (VR), Augmented Reality (AR), Augmented Humans $(\mathrm{AH})$, and Mobile Artificial Intelligence (MAl) have become a vital aid in the creation of three-dimension (3D) digital models and development of design environments (Manzoor, Othman, and Pomares 2021). These techniques have the potential to change the nature of the design process and facilitate collaboration with others.

The new technologies provide a new way of participation that allows participants to get access to a broad range of information and experiences, feel the effects of deep change, and develop themselves. The lay public is becoming more comfortable with these technological tools.

Perception: A Case Study of Students' Visualization of Urban Space. DOI: http://dx.doi.org/10.5821/ace.16.47.9886 
This familiarity with these tools can substantially improve public participation in urban design and space visualization (Lanza and Tilio 2010). Actually, these technological innovations extend the scope of participation methods and add new dimensions to civic urban attachment (Sameh 2011). They give the citizens new probabilities and forms of participation in the design process. They provide tools that help people participate, interact with them effectively, and get involved in decision making in a more interactive way (Reinart and Poplin 2014). This can improve communication between the decision makers and the citizens (Hanzl, 2007; Fares et al., 2018).

The challenge in these technologies is to develop appropriate programs such that the associated techniques will fit the goal, which is to involve urban participation and build a direct connection between this participation and the decision-making process (Hanzl 2007). New visualization technologies have attracted a high proportion of residents. Data visualization had removed barriers to civic engagement and promoted decision communication (Williams 2016). Moreover, they had a positive impact on citizen's attachment during co-design sessions (van Leeuwen et al., 2018). The most productive form of presentation of design solutions is 3D graphics that demonstrate building and urban context development. The 3D models are presented as static pictures in the form of physical models or animated as virtual models or digital models. Three-dimension modeling and visualization programs provide new means of involving citizens in the city development process. The goal of creating 3D city models is to represent the urban process taking place in the city. It is to make this process easy to read and understand and to assess design issues to support discussion (Hanzl 2007).

Visualization methods are reliable tools that can enhance the interchange of viewpoints between decision makers and the public in order to, ultimately, increase the effectiveness of the participation process (Fares, Taha, and Sayad 2018). What is required, then, from the use of visualization technologies is elimination of obstacles to urban participation and taking part in decision making (Williams 2016). In effect, the visualization technologies are necessary for assessment of proposals, evaluation of alternatives, and development of new solutions in order to create simple tools that are easy-to-understand and use by the majority of the community groups (Fares, Taha, and Sayad 2018).

\subsection{Game-based Urban Perception}

The game software have many tools with great potentials that can be used in architecture, planning, and urban design (Poplin, 2012). Emerging innovative technologies like VR, Emerging Technology (ET), which depends on mixing reality, and immersive technology in the field of game-based applications promote new forms of communication between citizens, planners, and realm entities (Poplin, 2012; George, 2019). Several game-based applications allow participants to take part in decision making at the early design stages based on advanced simulation and visualization of a certain urban design (Fares, Taha, and Sayad 2018). Game-based urban perception has become an appealing field of study in urban design and planning. It was developed in an effort to improve users' understanding of context through visualization media (Zhang, Shen, and Liu 2018).

Game technological applications provide great opportunities for production of 3D graphics in real time using hardware support (Hanzl 2007). These applications produce 'photo-realistic' graphics that reflect a real-life world (Hanzl, 2007; Voigt et al., 2003). The basic function of urban design visualization is not only communication, but also provision of more realistic representation of the environment for the viewers based on two-dimensional (2D) images or plans by creating 3D applications that make the representation of the real world as much realistic as possible (Rosmani et al., 2014; Indraprastha \& Shinozaki, 2009; Ratcliffe \& Simons, 2017).

Interactive game applications can deliver real-time, highly-reliable visualization in interactive media that can be implemented by numerous devices (Fares, Taha, and Sayad 2018). As a result, these

ACE, 16 (47) CC BY-ND 3.0 ES|UPC Barcelona, España | Integrating 3D Game Engines in Enhancing Urban 3 Perception: A Case Study of Students' Visualization of Urban Space. DOI: http://dx.doi.org/10.5821/ace.16.47.9886 
applications are designed to create highly-detailed and realistic representation of environments that allow users to walk across them as if they were really there (Ratcliffe and Simons 2017).

The visualization developers can use 3D video game engines that provide strong feature sets to support perception. In the world of games, immersion is the process of making a player part of an experienced game. It is about the degree of player involvement in a certain digital game. This involvement is influenced by virtual factors such as sounds, graphics, and textures, in certain cases (Alatta and Freewan 2017). The game player receives effects from all technological sensory modalities in a manner that preserves quality of the equivalent real-world effects. For example, the properties of the human field of view (FOV) in the game environment are much related in nature to human characteristics. One of the strongest positive points in the game environments is that, in these media, the player feels in control; she/he can freely visualize, perceive, and explore the world she/he got immersed in and experience it with her/his own actions in state of actions associated with, and determined by, a pre-defined walkthrough track (Denisova and Cairns 2015).

It is also possible to confirm the future use of game engines as stimulating computer-based tools that can potentially include citizens in a serious urban participatory processes (Poplin, 2011). These tools can help them to get engaged in the urban process and to understand its product with pleasure and joy (van Leeuwen et al., 2018; Zhang et al., 2018). Playful urban participation using game engines allows the participant the opportunity to get the maximum level of urban perception and involvement while playing. Its focal theme is ensuring pleasure and enjoyment for the citizens involved in the urban participatory processes (Lanza and Tilio 2010). It is an effective participation method that makes its users feel being 'in flow' during the participatory process (Krek, 2008). It emphasizes the emotional impact that attracts attention of the citizens and engages them with a high level of urban understanding. Games have the ability to involve citizens in serious participation without binding or rationalizing them (Krek, 2008; Poplin, 2012).

The game technologies can improve the teaching and learning of urban design by taking advantage of information and communication technologies (Kirkwood and Price 2014; Rengifo et al. 2021). They can support students' way of realizing and understanding the real environment with meaningful and worthwhile questions. Moreover, they can enhance their feeling of the available data such that they may design and conduct manageable investigations (Hug, Krajcik, and Marx 2005). In this regard, many studies have been conducted; some were reviews that focused on evaluating the technology itself or its discipline area while others were analyses that concentrated on providing meta-analysis or focus analysis of findings of experimental studies (Kirkwood and Price 2014). In this respect, this study investigates the impact of using interactive 3D game environment on users' involvement. The study also examines how this environment affects their experience and perception and whether, or not, it enriches their spatial recognition.

\section{Methodology}

With the aim of Al-Balqa' Applied University to make theoretical sciences, practical and applicable. The urban design undergraduate course engaged fourth-year students in developing urban spaces within their local environments. They were directed to develop the commercial area in Sweileh district (Amman, Jordan) and suggest interventions that can enrich the urban setting in that area. They were asked to identify and document the problems which the area under study faces through photos, videos, observations, and civic participation (interviews with locals and questionnaire surveys) during site visits.

ACE, 16 (47) CC BY-ND 3.0 ES|UPC Barcelona, España | Integrating 3D Game Engines in Enhancing Urban

Perception: A Case Study of Students' Visualization of Urban Space. DOI: http://dx.doi.org/10.5821/ace.16.47.9886 
Then, they were asked to suggest a strategy to solve the problems of building overlapping, traffic jams, transportation problems, and unstructured building facades in this study area. They were also guided to develop pedestrian movement routes, public spaces, social activity supports, and signage systems. The workflow of the development criteria is illustrated in Figure 1.

Figure 1. Workflow of the process of development of Sweileh commercial area

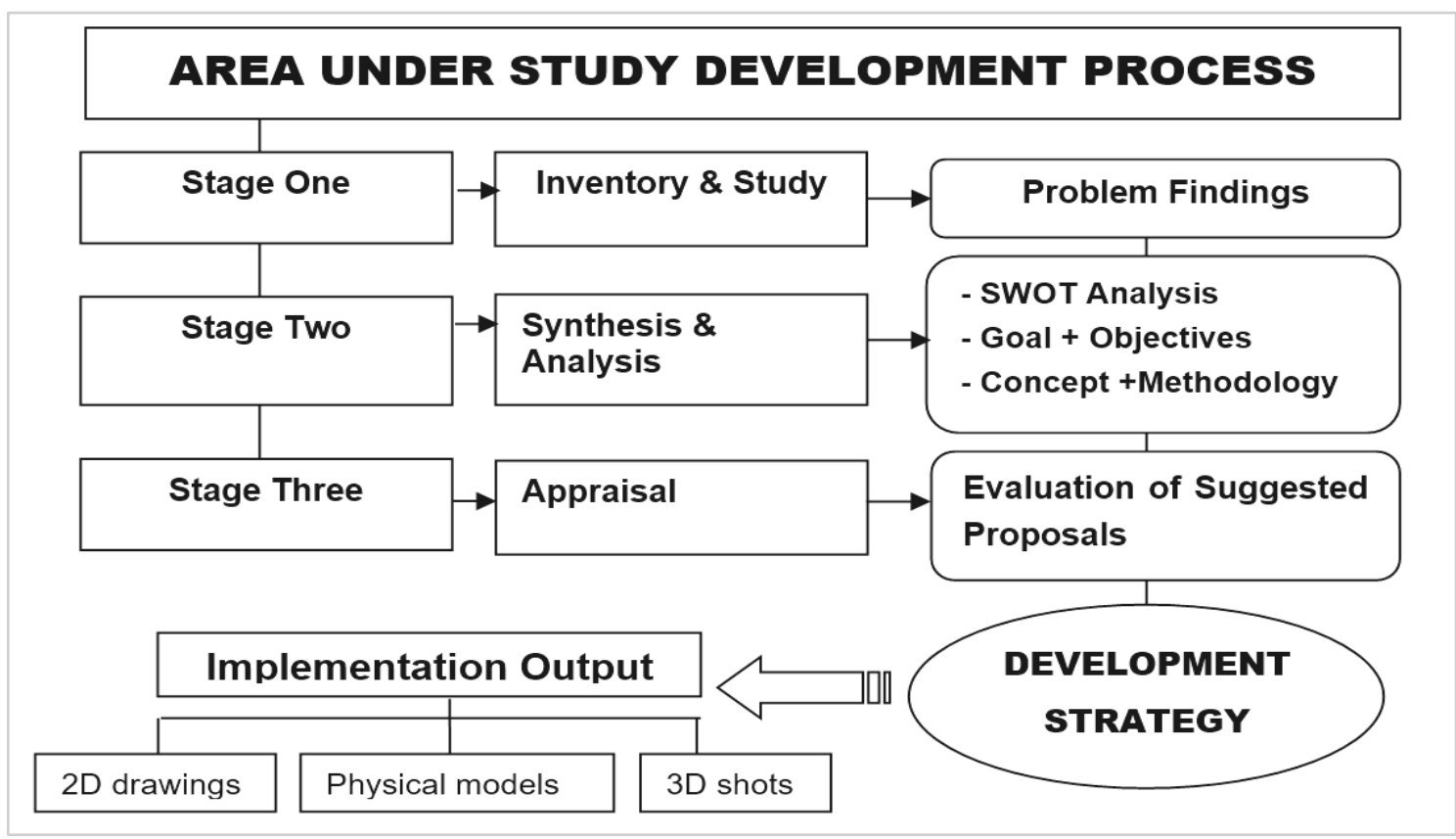

Source: Synoptic method in urban design/ Prepared by the authors, 2021.

The process of development of Sweileh commercial area entailed preliminary analysis of the strengths and weaknesses of the area, the opportunities in that area and its environment, and threats (SWOT analysis). This analysis was intended to identify the problems of the area and generate alternatives to achieve a sustainable and progressive development of this area. The urban design course students used different techniques to transform their ideas into work stages.

This was accomplished by 2D digital drawings, physical models, and 3D shots as shown in Figures 2, 3 , and 4, respectively. Although manipulation of Styrofoam, cartoon, and metal pins to construct physical models of the proposed developments require higher skills and used to consume longer time than 2D drawing, it provided the students with deep understanding of the urban spaces. On the other hand, digital models and videos were more effective in generating graphics at low cost.

The digital 3D model of the developed area was exported from Autodesk Revit Software to 3D Unity, which is one of the most familiar game engine software that enables development of a real-time environment. Unity is a free real-time game engine that allows rendering, visualization, and navigation of 3D models to mimic and simulate the real world (Figure 5). Incorporating the Revit model into the 3D Unity software aimed at creating an interactive walkthrough by means of the Unity Asset Store. The asset store is a pre-prepared, easy-to-use Unity library of free assets covering textures, models, characters, and animations of detailed environments that facilitated students' work to promote the 3D (gaming) model or project. 


\section{ACE Architecture, City and Environment}

Figure 2. 2D drawing to delineate the intervention sites in Sweileh commercial area (Technique 1)

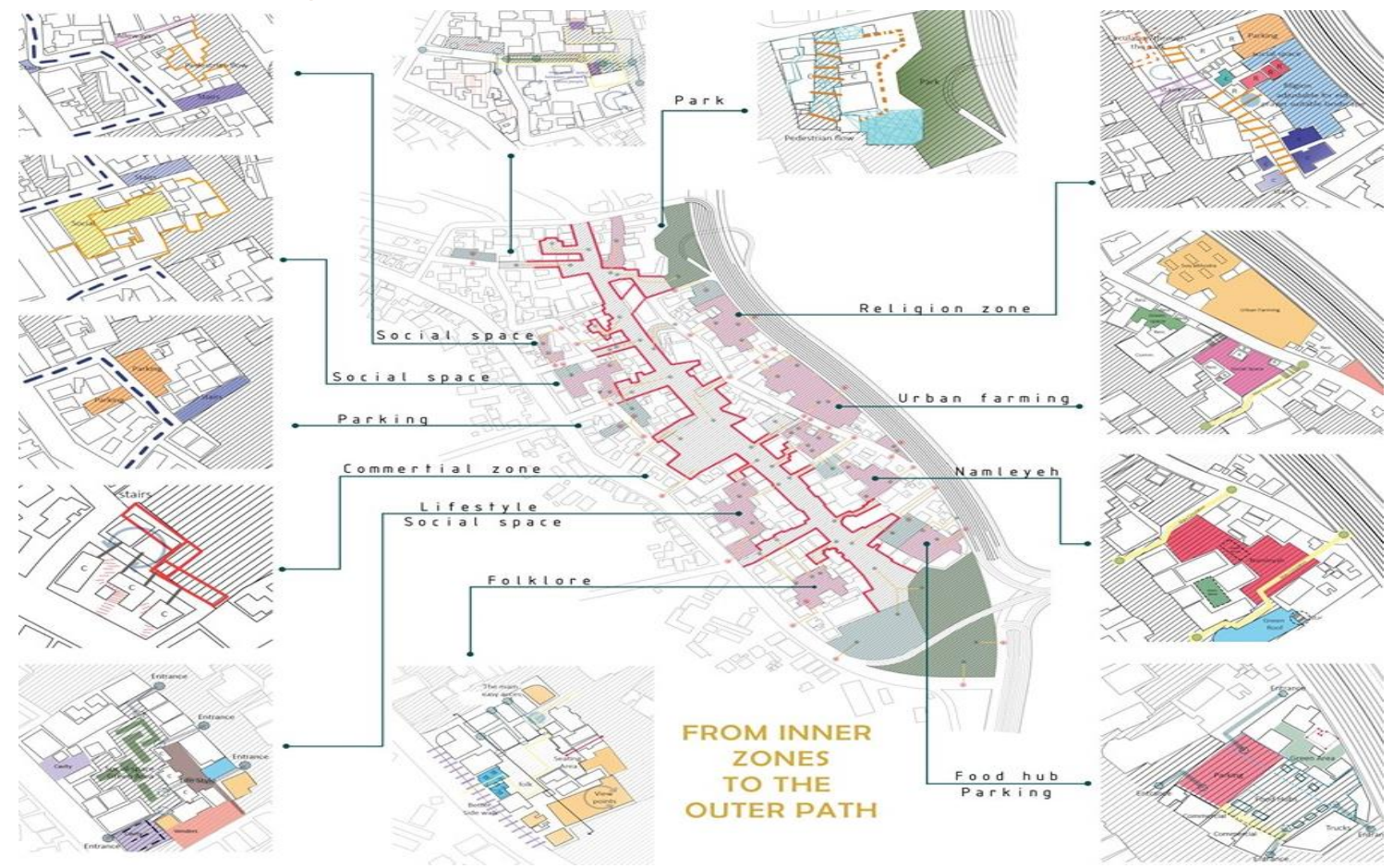

Source: Fourth-year students' suggestions/ CAD, 2021.

Figure 3. Physical models of developments of Sweileh commercial area (Technique 2)
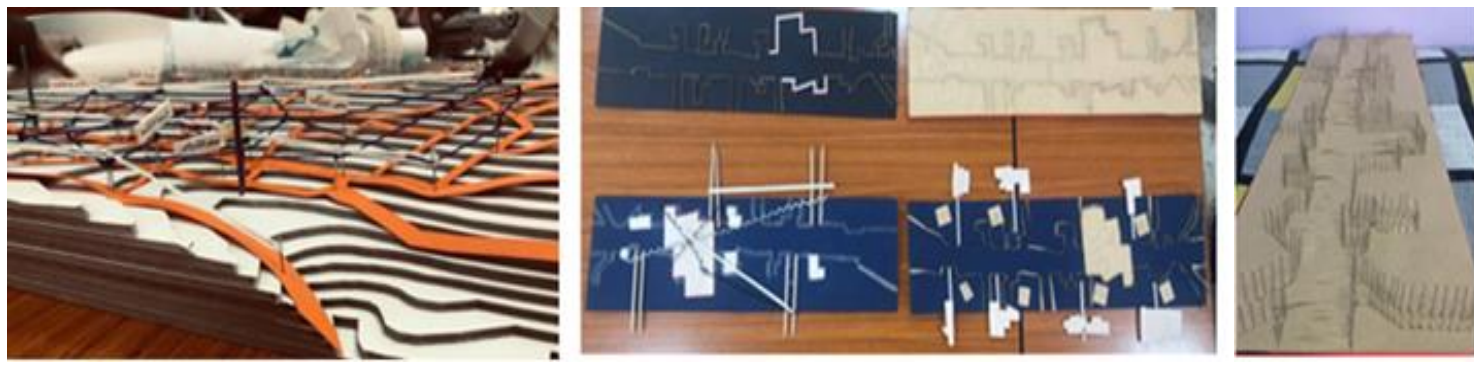

Source: Fourth-year students work, 2021

Figure 4. 3D shots corresponding to examples of animated videos of suggested upgrading of the commercial area in Sweileh (Technique 3)
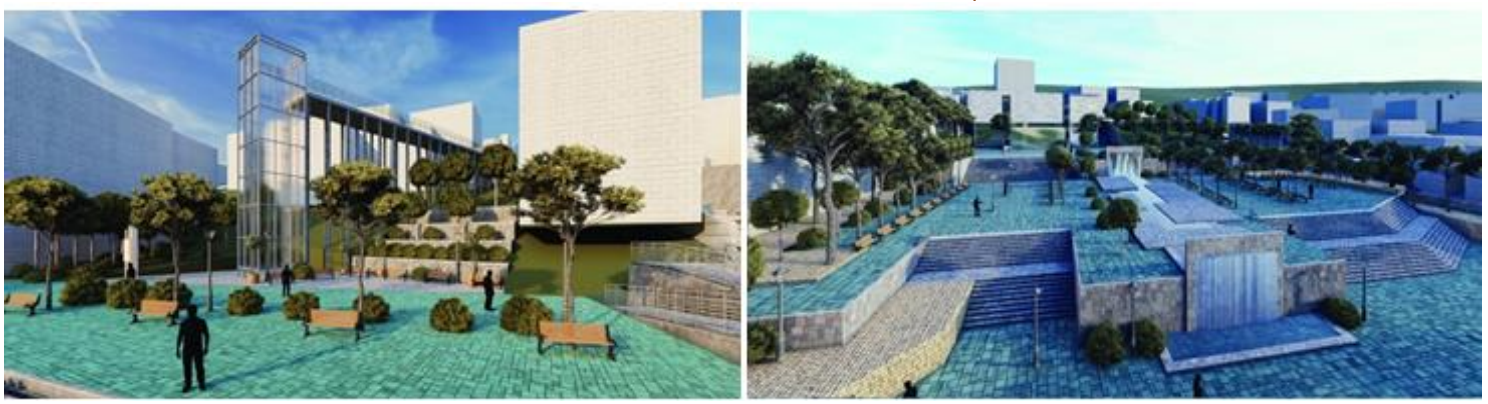

Source: Lumion 3D rendering software, 2021

ACE, 16 (47) CC BY-ND 3.0 ES|UPC Barcelona, España Integrating 3D Game Engines in Enhancing Urban 


\section{ACE Architecture, City and Environment}

Figure 5. Unity real-time fast photo realistic rendering (Shots of the developed alley, stairs, and part of façade of one building in the commercial area in Sweileh that have been drawn from the interactive 3D real-time demo)
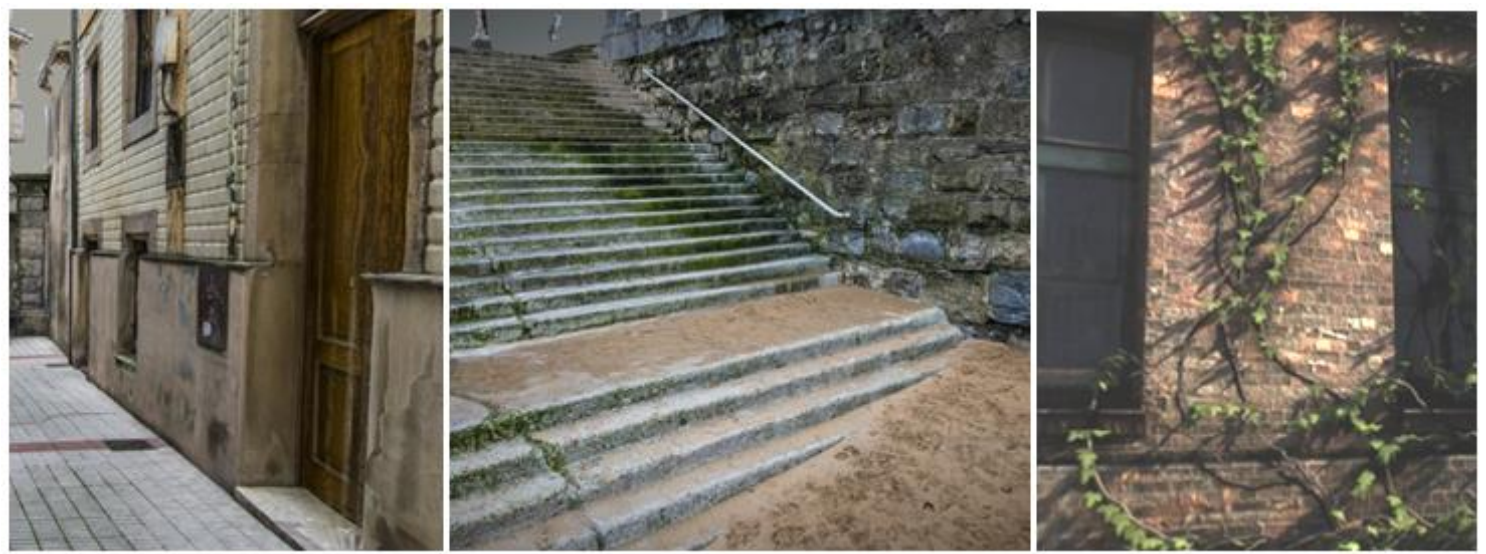

Source: 3D Unity, 2021.

\subsection{Procedure}

A sample of 15 volunteering undergraduate students at Balqa University who are residents of Sweileh district were randomly selected. As these students did not have a background in urban design, they were enrolled in explanation sessions to inform them about urban design and its components before execution of this study. After that, they were divided equally into three groups of five members, each. Then, the members of each group of volunteering students were directed to explore the developed spaces in and around their living places in one of the following ways (Figure 6):

\section{Physical models}

Physical models having the scale of 1:1000 and the dimensions of one A3 sheet were created to show topography of the study area. These models also showed street networks, the developed paths, and traffic solutions. Other physical models of a scale of 1:200 that were made up of corrugated cardboard, cartoon, and metal pins were also constructed to show the main street which had been transformed into pedestrian path and a suggested plaza.

\section{Animated video}

Each animated video corresponded to basic walkthrough video recording of a duration of three minutes that was recorded using Lumion 3D rendering software. The participants were exposed to each of these videos twice. The video scenes start from Sweileh circle, progress through the pedestrian path, and end at the suggested plaza, with associated views of the facades of the surrounding buildings.

\section{Interactive real-time demo}

A high-quality, virtual, real-time demo was developed to interactively visualize the upgraded area in Sweileh. A directional gamepad with a trigger button in the center of the control pad ('Enter' button) allowed the participants to start their experience with the demo for a duration that does not exceed three minutes. The four-way directional controllers and direction buttons (up and right, for example) of the control pad were used to allow the browser to navigate easily and smoothly wherever she/he wants within the developed area.

Before the last group started the experiment, they were given a short tutorial that aimed at familiarizing them with the game environment and its controllers (Sigma Logitech gamepad). The trailed tutorial and the demo itself were set on a first-person camera. Use of the first-person 
camera represented an attempt to get the participant immersed in the game by herself/himself, not by a specific character or an avatar as is the case when using third-person camera (Gorisse et al. 2017). This was intended to ensure immersion and to stimulate the player to feel the demo rather than to witness avatar actions.

Figure 6. Students' participation in visualization of the area under development via three methods: physical models, animated video, and interactive demo
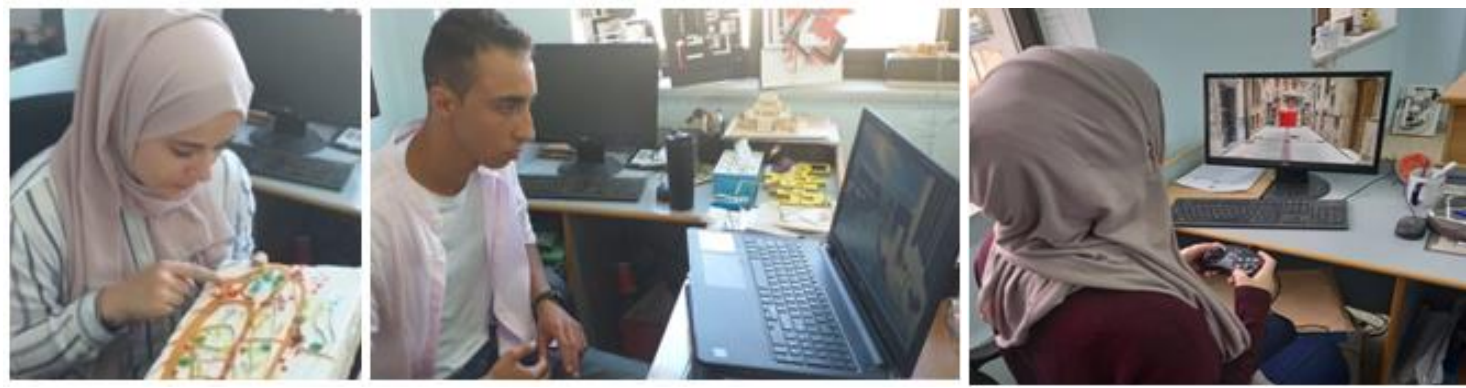

Source: Prepared by the authors, 2021.

Then, the participating students were given a questionnaire (using Google Docs) after seeing the area developments using one of the three methods. The questionnaire consisted of two parts: an introduction to the questionnaire and an opinion part.

Part 1: Introduction

Part 2: A survey of the participants' opinions about the used visualization technique. The survey questions addressed the following issues:

- Effectiveness of the visualization methods

Effectiveness of the employed visualization method assesses ability of the used expression method to provide an enabling and efficient environment that can assist the participant to interact with the content and get her/him totally involved in the visualization experiment without hesitation.

- Interactivity of the participant

Interactivity of the participant assesses the degree of interaction of the participant and the degree of freedom of navigation of the design developments which the visualization tool allows for. It is measured by participants' explanations of their experience during the experiment in the visualization environment.

- $\quad$ Participant's perception of details of the design developments

Participant's perception of details of the design developments evaluates participant's perception of the urban spaces and her/his judgment on them. It seeks to determine how the proposed medium can facilitate their recognition and the extent of understanding of what they experience during visualization using the certain medium.

- Need for team assistance

Need for team assistance evaluates participant's ability to explore and understand the proposed design through the expression technique with minimal guidance.

- Inspiration to create new ideas

This measure assesses ability of the visualization medium to motivate the participants to generate alternatives and innovative solutions to modify their urban living spaces. 


\section{ACE Architecture, City and Environment}

Figure 7. Examples of mental maps (given to volunteer students): the original map of the developed commercial area (temple), region imagibility map (layer 1) \& visual appearance interventions (layer 2)

Layer One Legend Key

Source: Prepared by the authors, 2021.

Figure 8. Students' participation in visualization of their developed residence areas.

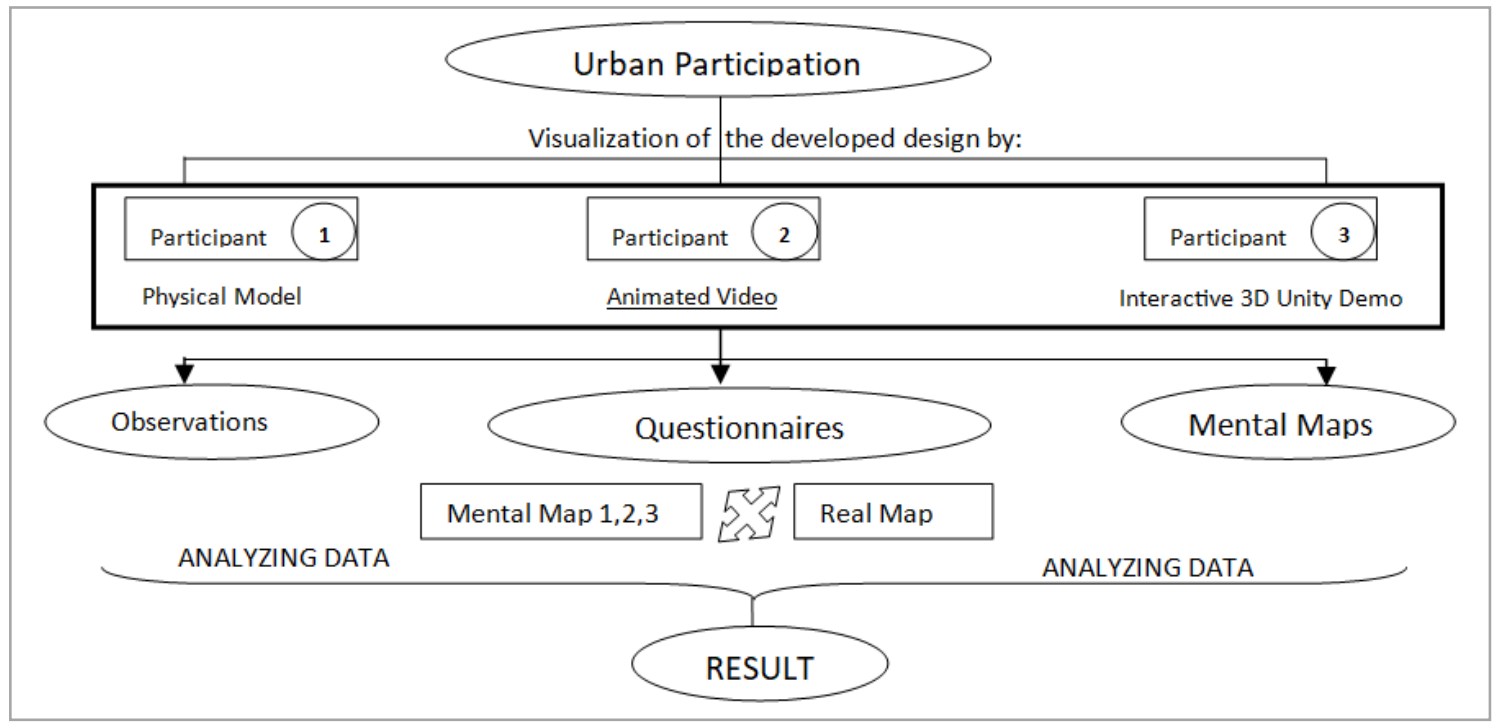

Source: Prepared by the authors, 2021. 
In addition to the questionnaire, the participants were asked to express their understanding of the new design. They were asked to fill a pre-prepared mental map with information for this study to determine their level of understanding of the area and its detailed visual appearance in view of the proposed development. They were to use symbols illustrated with a key to fill two layers of their mental maps. The first map layer pertains to the elements of the developed area imagibility while the second layer is related to the detailed interventions in the visual appearance of the developed study area as illustrated in Figure 7.

Observations were also made to study the reactions of the participants and the workflow of the experiment. The outputs of the observations, questionnaire survey, mental map drawings, research team's feedback, and textual documentation were classified and analyzed to obtain the study results as shown Figure 8.

\section{Experimental results and discusión}

\subsection{Observations}

The observations showed that remote watching of conventional 3D models could not help most of the participants much understand the proposed development due to scale problem and to its passivity, and limited viability for expression of some features and effects like light effect, materials, and colors. It is noticeable that members of Group I tried to imagine themselves being in that place walking through their spaces. Most of this group members were confused, and they asked the team members many questions. They had an effort to reach to an appropriate understanding of the study area rather than focusing on the adjustments and expressing their opinions about the planned development of the study area. Participants' descriptions of their experience after using the physical models reflected that most of them did not reach to a satisfactory understanding of the developed area.

On the other hand, visualizing the area with an audio clip (convenient for walking in an urban setting) that was prepared by the research team gave better results than remote watching. The participants watched the animation video with pleasure. They imagined that they were walking through the developed area sequentially at a specific time. But the walkthrough animation of the pre-defined path and the restricted point of view had limited the whole interactivity. The participants were restricted to choose what to look at and where to move. The animation video determined participants' field of view and confined their ability to look where they want. Therefore, their recognition of the developed area was somewhat far from complete.

Otherwise, students who experienced the proposed development of their living area in the game environment interacted effectively with the suggested urban design. They received visual, interactive audio demonstration of the development and nearly realistic tactile data from 3D Unity realistic rendering that showed textures, colors, and materials. They experienced the narrated storyline of the developed zones with all their details. The game visualization technique resulted in a higher level of engagement of participants than visualization using the physical models and the walkthrough video. The game environment was highly interactive; it provided the participants with a freedom to choose navigation alternatives in a playful interactive way like what can be encountered in the real world as illustrated in Figure 9. Their control over navigation anywhere they wanted imparted them with satisfactory control over the navigation direction and speed and timing of movement within the demo environment. It was also noticed that the 3D Unity preface improved particpant's inclusion in the development environment. The particpants enjoyed exploring the developed spaces of their living areas. Students' verbal explanations of this experiment revealed that most of them reached to a clear view of the developed residence. Furthermore, they suggested new alternatives for its development.

ACE, 16 (47) CC BY-ND 3.0 ES|UPC Barcelona, España Integrating 3D Game Engines in Enhancing Urban 10 Perception: A Case Study of Students' Visualization of Urban Space. DOI: http://dx.doi.org/10.5821/ace.16.47.9886 
The particpants who used the interactive game technology achieved better understanding of the proposed development than their peers who viewed the same area using other means. Understanding important facets of the proposed development of the study area like scale, site layout, development details, and the design itself, affected participants' level of involvement.

Figure 9. Comparison between Lumion generated video and the real-time 3D Unity software demo

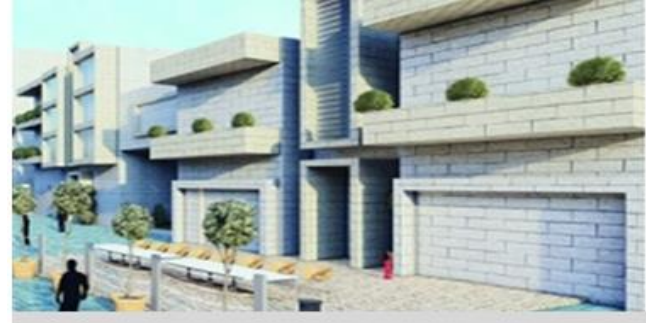

Restricted interaction animation

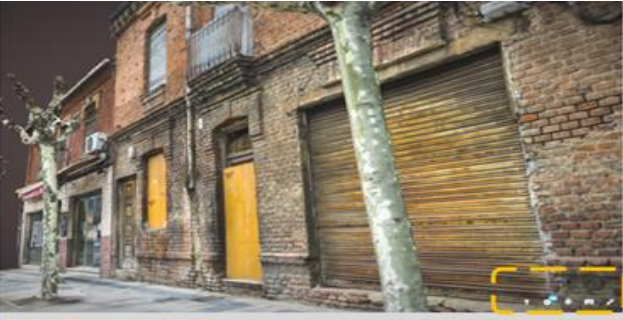

Free navigation bottoms

Source: Prepared by the authors, 2021.

\section{Questionnaires}

The data obtained from the questionnaire were analyzed using the SPSS software. Regarding students' interactions while seeing their residences after the proposed urban development, all five students of the third group (100\%) revealed that they interacted well with the demo content. The participants' responses indicated that the most notable benefit of the interactive medium is its effectiveness in involving them in the experiment. The same group participants (100\%) agreed on this. Meanwhile, the digital medium and the traditional medium were rated as involving media by $75 \%$ and $25 \%$ of the participants, respectively. As regards perception of the developed area, the proportions of participants supporting the interaction benefit of the environment of the interactive, digital, and traditional media were 95\%, 59\%, and 20\%, respectively.

Figure 10. Comparison between the traditional, digital, and interactive visualization methods in terms of their effectiveness and participant's interactivity, perception, inspiration, and need for guidance.

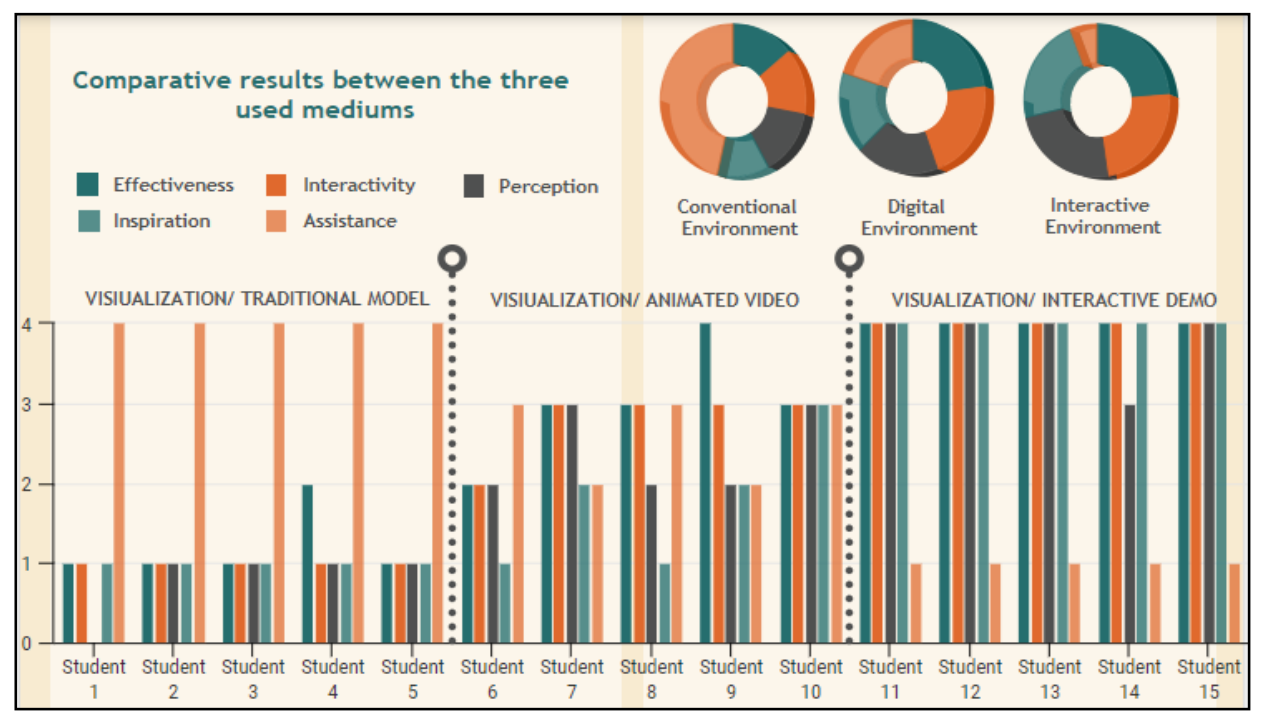

ACE, 16 (47) CC BY-ND 3.0 ES|UPC Barcelona, España | Integrating 3D Game Engines in Enhancing Urban 
Source: Prepared by the authors, 2021.

In other respects, the percentages of participants supporting ability of the three studied media to motivate thinking of innovative ideas for the future of their localities were 100\%, 45\%, and 25\%. However, the proportions of the participants who stressed the need for team assistance during the experiment when using the interactive, digital, and traditional media were 25\%, 65\%, and 100\%, respectively. The results of quantitative analysis confirm that the interactive game is the best visualization method in terms of effectiveness, interactivity, perception, and inspiration (Figure 10).

The K-independent samples test (Kruskal-Waliis H Test) was conducted to test the research hypothesis. It showed that differences between the five comparative categories in preference for the three types of urban participatory visualization environments are statistically significant (Asymp. Sig. value ranged from 0.001 to $0.002, p<0.05, \mathrm{df}=2$ ). The test results pointed out that the interactive medium had the highest mean rank in terms of interactivity, effectiveness, perception, and inspiration and the least mean rank in terms of the need of for team guidance or assistance, as shown in Tables 1 and 2 .

\section{Cognitive maps}

Both layers of the mental maps of the participants who used the interactive medium were different from the corresponding layers in the cognitive maps of the students who used the ordinary software. The former participants perceived their developed residence in a different way from the latter participants who used ordinary media. They did not identify the same elements through the interactive or conventional exploration of the mental maps of the developed area. The mental maps reveal that participants perceive their developed residence design more actively in the interactive game environment than in the ordinary and conventional environments.

Figure 11. Example of imageability mental maps produced by participants using the three visualization methods

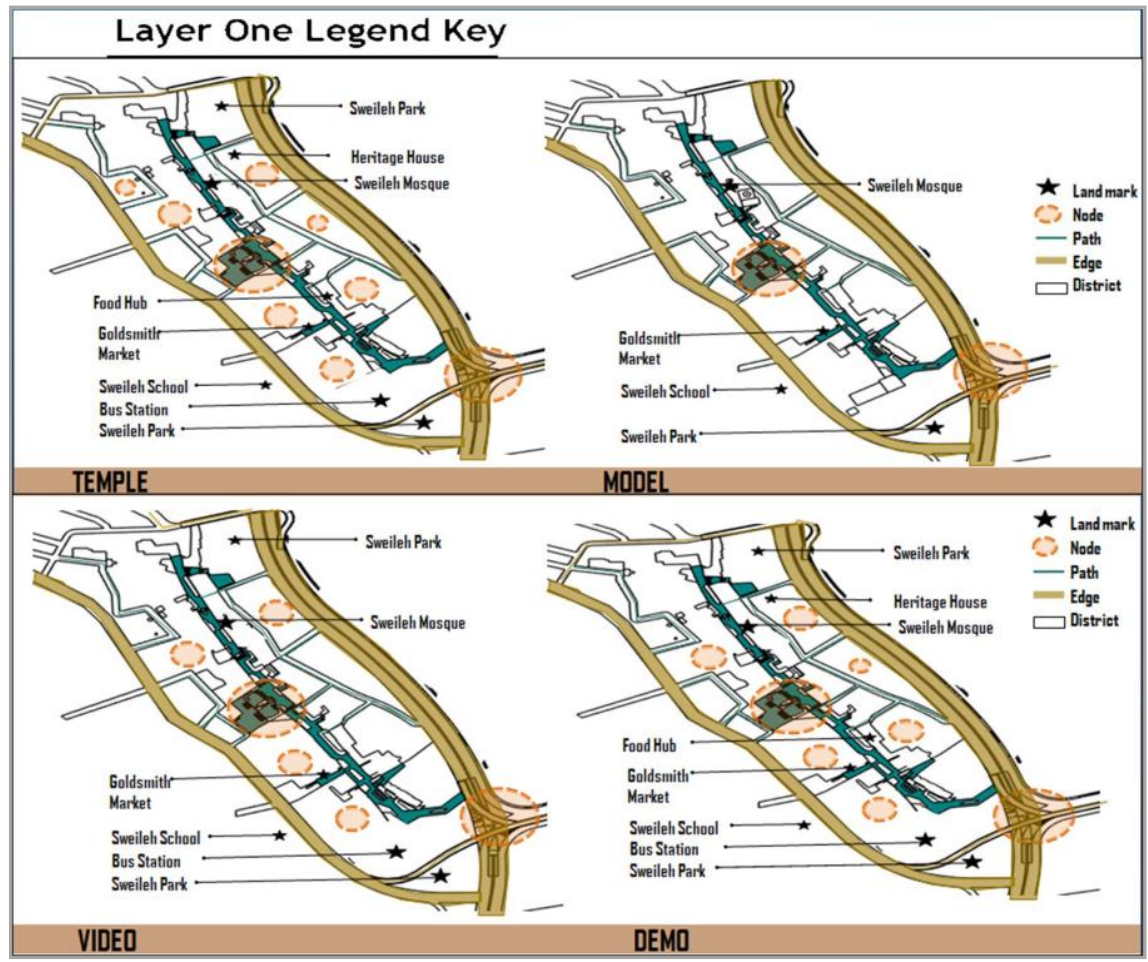

ACE, 16 (47) CC BY-ND 3.0 ES|UPC Barcelona, España | Integrating 3D Game Engines in Enhancing Urban

Perception: A Case Study of Students' Visualization of Urban Space. DOI: http://dx.doi.org/10.5821/ace.16.47.9886 
Source: Prepared by the authors, 2021.

Imageability perception of the developed area: The lack of freedom to move in and around the developed area in the physical and digital visualization led to incomplete view of the proposed development in comparison with the freedom to move found in the interactive exploration. Exploration via the interactive game environment allowed for a non-restricted design visualization, thus resulting in an almost complete understanding of of the development by the participants.

Results of analysis of the imageability mental maps showed that $90 \%$ of participants achieved an excellent understanding of Lynchian elements while exploring the suggested design interactively. Nearly 58\% of the members of Group I read all landmarks of the study area. However, all of them recognized the main middle plaza only due to its large area. Meanwhile, only $77 \%$ of them realized the main pedestrian path and all edges of the study area. On the other hand, around $70 \%$ of the members of Group II captured the main features of the study area (Chechnyan's Mosque, Al-Sharkas Mosque, Sweileh Park, Sweileh school, etc). They described the main path, most of the edges of the area, the plaza (as being a main nod), and nearly 50\% of the secondary nodes. About 95\% of the members of Group III were able to perceive and explore everything that they wanted to. They recognized the pedestrian paths and developed alleys, the main plaza with its design details, secondary plus tertiary nodes, and nearly most of the landmarks of the study area (Figure 11, Table 3).

Table 1, 2. Kruskal-Waliis H Test results

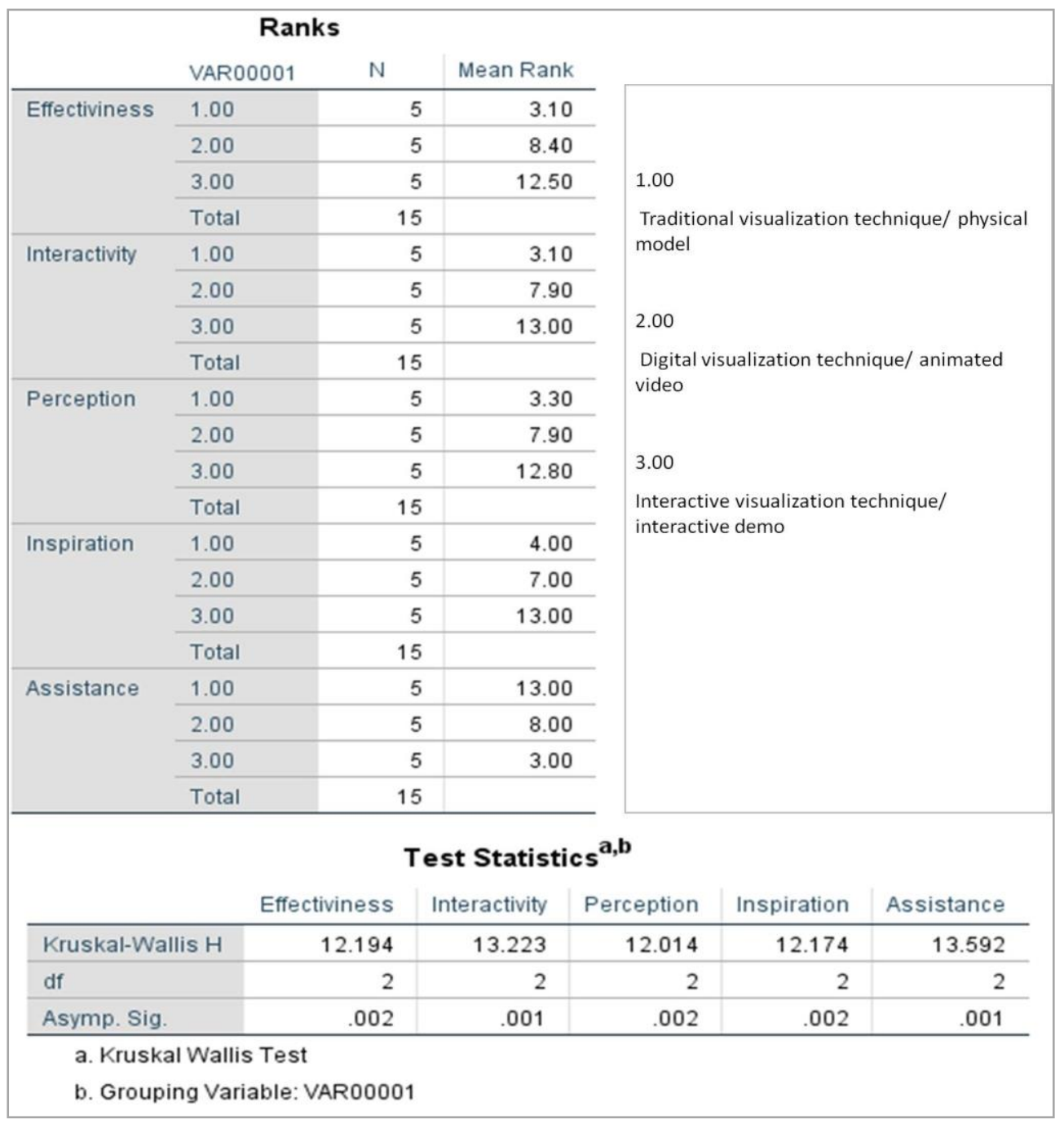

ACE, 16 (47) CC BY-ND 3.0 ES|UPC Barcelona, España | Integrating 3D Game Engines in Enhancing Urban

Perception: A Case Study of Students' Visualization of Urban Space. DOI: $\underline{\text { http://dx.doi.org/10.5821/ace.16.47.9886 }}$ 
Source: Prepared by the authors, 2021.

Detailed visual appearance perception: Analysis of the second layer of mental maps uncovered that the volume of visual information spotted on the maps by the members of Group III was higher than those provided by the other two groups of students. The difference in details between the interactive and physical visualization methods led to differences in participants' perceptions of the developed area. Unity 3D real environment provided more details than the other employed visualization methods. The conventional exploration gave a general overview of the environment, but lacked the specificity and details gained from the interactive exploration. Some participants identified specific details in the interactive environment, which their peers could not see in the conventional medium as indicated in Figure 12 and Table 4.

Table 3. Sorting of participants' data in the first layer of the mental maps

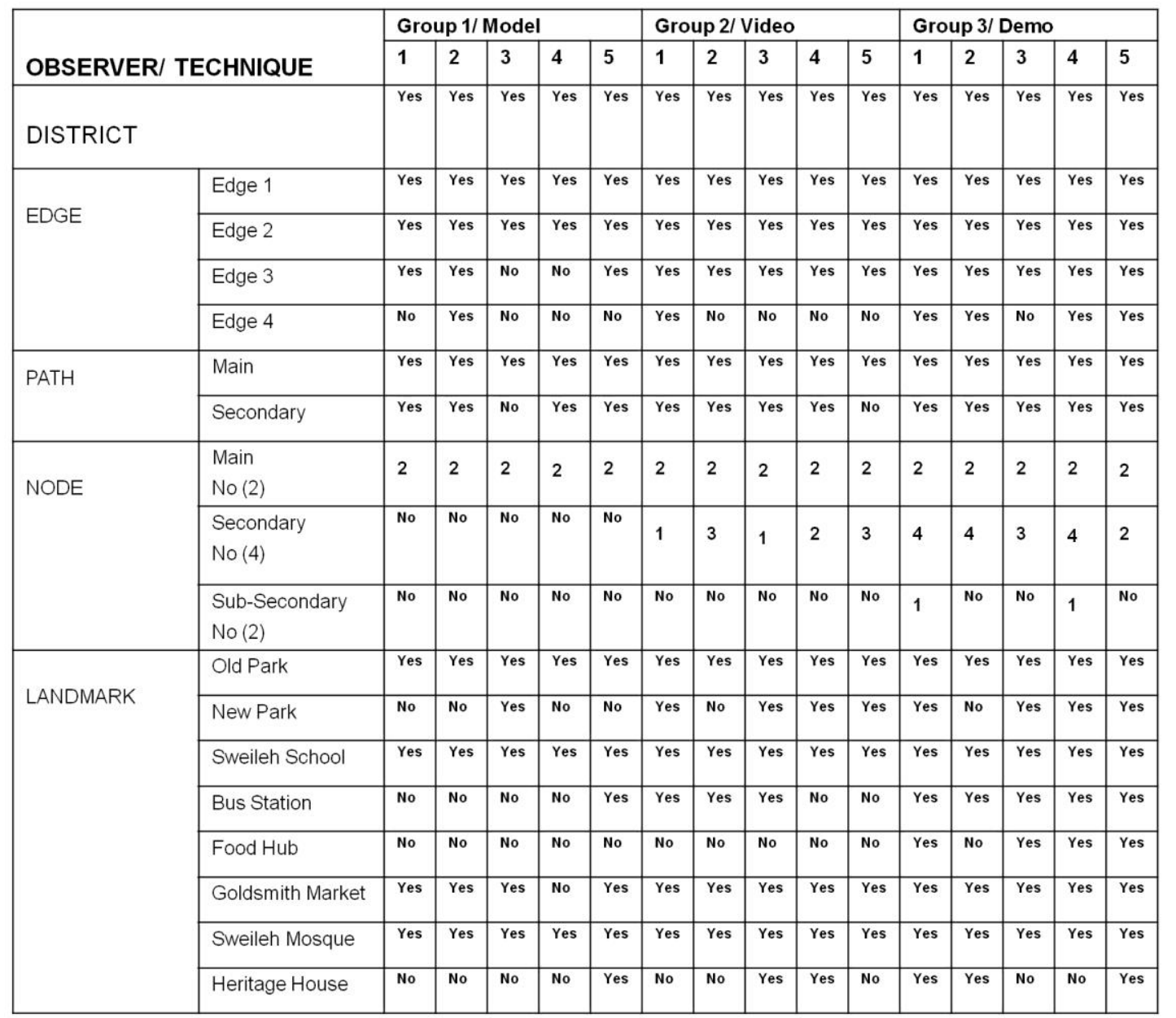

Source: Prepared by the authors, 2021.

\section{Conclusions}

This research paper has shown that using game engines in the urban design participatory process enhances understanding of the urban environment. It provides an interactive, real-time, and stimulating process that can incorporate residents so that they can recognize, understand, and experience urban solutions in a novel way. This enriches the spatial perception of design. It simplifies 


\section{ACE Architecture, City and Environment}

visualization and provides an effective, efficient, and interactive medium that supports people's participation in the workflow of the urban design project. Using game engines for design visualization facilitates urban communication with designers and improves urban involvement in the design itself in an innovative way. Accordingly, this study demonstrates benefits of the interactivity of the game applications which positively affects participants' ownership and freedom of visualization, hence leading to detailed real exploration. This enhances the feeling of urban attachment and improves perception of the urban design process. As well, this triggers people's imaginations to suggest new design ideas, solutions, and alternatives through their direct involvement in the participation process. Moreover, this study confirms the benefits of using game visualization to enhance urban perception over that obtained from the traditional techniques.

Figure 12. Example of detailed mental maps produced by participants using the three visualization methods

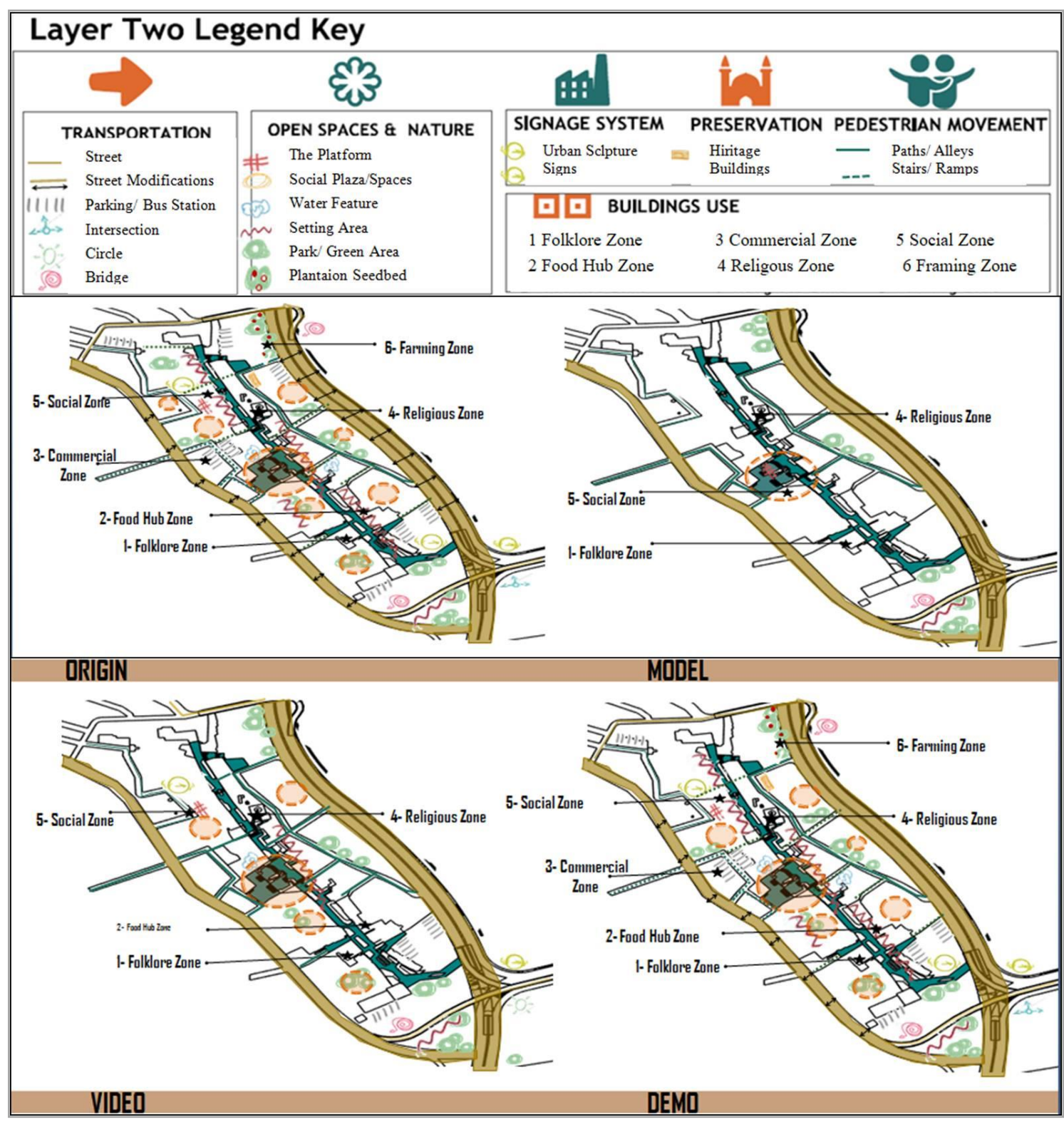

Source: Prepared by the authors, 2021.

ACE, 16 (47) CC BY-ND 3.0 ES|UPC Barcelona, España | Integrating 3D Game Engines in Enhancing Urban Perception: A Case Study of Students' Visualization of Urban Space. DOI: http://dx.doi.org/10.5821/ace.16.47.9886 
In other respects, this study emphasizes the role of technology in enhancing the user's learning experience. The current results also show how using such interactive media as those considered in this study can minimize the difficulties which the students face in practice. Furthermore, results of this study explain how such media can give the students, as future designers, the opportunity to examine their designs and interactivity of the users with the urban space.

The researchers conclude that the interactive visualization media can transform the industry of place making through focusing on urban involvement. By taking advantage of technological applications and associated benefits, the designers, office workers, and decision makers can make innovative products that meet people's needs and cope with real market requirements.

In conclusion, the interactive game technology can engage residents in the urban design process effectively and interactively. It may be of interest to researchers to study the effect of using VR, AR, and other Artificial Intelligence tools on efficiency of communication between students, citizens, designers, and planners and to examine how, and to what extent, their use can reduce the comprehension gap between the different categories of participants in urban design.

Table 4. Sorting of participants' data in the second layer of the mental maps

\begin{tabular}{|c|c|c|c|c|c|c|c|c|}
\hline \multirow{2}{*}{ CATEGORY } & \multirow{2}{*}{ SUB-CATEGORY } & \multirow{2}{*}{$\begin{array}{l}\text { ORIGIN } \\
\text { MAP }\end{array}$} & \multicolumn{2}{|c|}{$\begin{array}{l}\text { MENTAL MAP } 1 / \\
\text { MODEL }\end{array}$} & \multicolumn{2}{|c|}{$\begin{array}{l}\text { MENTAL MAP } 2 \text { I } \\
\text { VIDEO }\end{array}$} & \multicolumn{2}{|c|}{$\begin{array}{l}\text { MENTAL MAP } 3 / \\
\text { DEMO }\end{array}$} \\
\hline & & & $\begin{array}{l}\text { Detected } \\
\text { Element } \\
\mathrm{s}\end{array}$ & Status & $\begin{array}{l}\text { Detecte } \\
\text { d } \\
\text { Element } \\
\text { s }\end{array}$ & Status & $\begin{array}{l}\text { Detecte } \\
\mathrm{d} \\
\text { Element } \\
\mathrm{s}\end{array}$ & Status \\
\hline \multirow{6}{*}{ TRANSPORTATION } & Street & 4 & 3 & $w$ & 4 & $w_{W} X$ & 4 & $\sqrt{w} \sqrt{ }$ \\
\hline & Street with modification & 2 & - & - & - & - & 1 & $\sqrt{ }$ \\
\hline & $\begin{array}{l}\text { Parking/ Bus Station or } \\
\text { Stop }\end{array}$ & 6 & - & - & 2 & w & 4 & $\sqrt{\sqrt{ } \sqrt{ }}$ \\
\hline & Intersection & 1 & - & - & - & - & 1 & $\sqrt{1}$ \\
\hline & Circle & - & 1 & $x$ & 1 & $x$ & - & - \\
\hline & Bridge & 2 & 1 & $\sqrt{4}$ & 1 & $\checkmark$ & 2 & $\sqrt{\sqrt{ }}$ \\
\hline \multirow{6}{*}{$\begin{array}{l}\text { OPEN } \\
\text { NATURE }\end{array}$} & The Platform & 1 & - & - & 1 & $\sqrt{ }$ & 1 & $\sqrt{1}$ \\
\hline & Social Plaza/spaces & 8 & 1 & 4 & 5 & $\sqrt{W} \downarrow W W$ & 7 & $\begin{array}{l}\sqrt{w w} \\
w w \\
w\end{array}$ \\
\hline & Water Feature & 2 & - & - & 1 & $\checkmark$ & 2 & $\sqrt{w}$ \\
\hline & Setting Area & 3 & - & - & 2 & $w$ & 3 & $\sqrt{W}$ \\
\hline & Park/Green Area & 7 & 4 & $\sqrt{W} \backslash \mathbb{W}$ & 5 & $\sqrt{w} w \times x$ & 6 & $\begin{array}{l}\sqrt{w W} \\
\sqrt{w}\end{array}$ \\
\hline & Plantation Seedbed & 1 & - & - & - & - & 1 & $\sqrt{ }$ \\
\hline \multirow[b]{2}{*}{$\begin{array}{l}\text { PEDESTRIAN } \\
\text { MOVEMENT }\end{array}$} & Paths/Alleys & 8 & 8 & $\begin{array}{l}W w W \\
w W w\end{array}$ & 8 & $\begin{array}{l}\sqrt{w} w w \\
w w w\end{array}$ & 8 & $\begin{array}{l}\sqrt{W W} \\
\sqrt{W}\end{array}$ \\
\hline & Stairs/Ramps & 8 & - & - & - & - & 5 & $\sqrt{W} \sqrt{W}$ \\
\hline SIGNAGE SYSTEM & Urban Sculpture/ Signage & 3 & 1 & $\sqrt{ }$ & 2 & $\sqrt{W}$ & 3 & $\sqrt{\sqrt{ }}$ \\
\hline PRESERVATION & Heritage Building & 1 & - & - & - & - & 1 & $\sqrt{ }$ \\
\hline \multirow{6}{*}{ BUILDINGS USE } & Folklore Zone & 1 & 1 & $\sqrt{4}$ & 1 & $\checkmark$ & 1 & $\sqrt{1}$ \\
\hline & Food Hub Zone & 1 & - & - & 1 & $\checkmark$ & 1 & $\sqrt{ }$ \\
\hline & Commercial zone & 1 & - & - & - & - & 1 & $\sqrt{ }$ \\
\hline & Religiouszone & 1 & 1 & $x$ & 1 & $\checkmark$ & 1 & $\sqrt{1}$ \\
\hline & Social zone & 1 & 1 & $\sqrt{4}$ & 1 & $\checkmark$ & 1 & $\sqrt{ }$ \\
\hline & Farming Zone & 1 & - & - & - & - & 1 & $\sqrt{1}$ \\
\hline \multicolumn{9}{|c|}{$\begin{array}{l}\sqrt{ }: \text { Elements that } w \\
X: \text { Unrecognized it } \\
\text { BER: Number of recos }\end{array}$} \\
\hline
\end{tabular}

Source: Prepared by the authors, 2021.

ACE, 16 (47) CC BY-ND 3.0 ES|UPC Barcelona, España I Integrating 3D Game Engines in Enhancing Urban 


\section{Authorship}

All persons who meet authorship criteria are listed as authors, and all authors certify that they have participated sufficiently in the work to take public responsibility for the content, including participation in the concept, design, analysis, writing, or revision of the manuscript.

\section{Conflict of interests:}

The authors certify that they have NO affiliations with or involvement in any organization or entity with any financial interest (such as honoraria; educational grants; participation in speakers 'bureaus; membership, employment, consultancies, stock ownership, or other equity interest; and expert testimony or patent-licensing arrangements), or non-financial interest (such as personal or professional relationships, affiliations, knowledge or beliefs) in the subject matter or materials discussed in this manuscript.

\section{Bibliography}

Alatta, Rawan Abu, and Ahmed Freewan. (2017). Investigating The Effect of Employing Immersive Virtual Environment on Enhancing Spatial Perception Within Design Process. ArchNet-IJAR: International Journal of Architectural Research, 11 (2), 219. DOI: 10.26687/archnet-ijar.v11i2.1258

Creighton, James L. (2005). The Public Participation Handbook: Making Better Decisions through Citizen Involvement. John Wiley \& Sons. PMID: 19521007

Denisova, A., and Cairns, P. (2015). First Person vs. Third Person Perspective in Digital Games: Do Player Preferences Affect Immersion? In Proceedings of the 33rd Annual ACM Conference on Human Factors in Computing Systems, 145-48. DOI: 10.1145/2702123.2702256

Fares, F., Taha, D., and Sayad, Z. (2018). Achieving Public Participation in Inaccessible Areas Using Virtual Reality a Case Study of Beit Hanoun-Gaza-Palestine. Alexandria Engineering Journal 57 (3), 1821-28. DOI: 10.1016/j.aej.2017.07.010

George, S. (2019). Games, Simulations, Immersive Environments, and Emerging Technologies. Encyclopedia of Education and Information Technologies. Springer International Publishing. DOI: $\underline{\mathrm{ff} 10.1007 / 978-3-319-60013-0 \quad 36-1 \mathrm{ff}}$

Gorisse, G., Christmann, O., Armand, A., and Richir, S. (2017). First-and Third-Person Perspectives in Immersive Virtual Environments: Presence and Performance Analysis of Embodied Users. Frontiers in Robotics and A/ 4 (2017), 33. DOI: 10.3389/frobt.2017.00033

Hanzl, M. (2007). Information Technology as a Tool for Public Participation in Urban Planning: A Review of Experiments and Potentials. Design Studies 28 (3), 289-307. DOI: 10.1016/j.destud.2007.02.003

Hug, B., Krajcik, J., and Marx, R. (2005). Using Innovative Learning Technologies to Promote Learning and Engagement in an Urban Science Classroom. Urban Education 40 (4), 446-72. DOI: $10.1177 / 0042085905276409$

Indraprastha, A., and Shinozaki, M. (2009). The Investigation on Using Unity3D Game Engine in Urban

ACE, 16 (47) CC BY-ND 3.0 ES|UPC Barcelona, España Integrating 3D Game Engines in Enhancing Urban Perception: A Case Study of Students' Visualization of Urban Space. DOI: http://dx.doi.org/10.5821/ace.16.47.9886 
Design Study. Journal of ICT Research and Applications 3 (1): 1-18. DOI: 10.5614/itbj.ict.2009.3.1.1

Kirkwood, A., and Price, L. (2014). Technology-Enhanced Learning and Teaching in Higher Education: What Is 'Enhanced'and How Do We Know? A Critical Literature Review. Learning, Media, and Technology 39 (1): 6-36. DOI: 10.1080/17439884.2013.770404

Krek, A. (2008). Games in Urban Planning: The Power of a Playful Public Participation: The Power of a Playful Public Participation. In M. Schrenk, V. V. Popovich, D. Engelke, \& P. Elisei (Eds.). Nodes as Innovation Hubs Verkehrsknoten als Innovations- und Wissensdrehscheiben, (2), 683-691. http://www.corp.at/archive/CORP2008 45.pdf

Lanza, V., and Tilio, L. (2010). An Operational Model towards Playful Public Participation. Proceedings/Tagungsband Vienna, 18-20 May 2010. Editors: Manfred schrenk, Vasily V. Popovich, Peter Zeile.

Lynch, K. (1984). Reconsidering the Image of the City. In Cities of the Mind, 151-61. Springer.

Manzoor, B., Othman, I., and Pomares, J. (2021). Digital Technologies in the Architecture, Engineering and Construction (AEC) Industry-A Bibliometric-Qualitative Literature Review of Research Activities. International Journal of Environmental Research and Public Health 18 (11), 6135. DOI: 10.3390/ijerph18116135

Marszal, A., Heiselberg, P., Bourrelle, J., Musall, E., Voss, K., Sartori, I., and Napolitano, A. (2011). Zero Energy Building-A Review of Definitions and Calculation Methodologies. Energy and Buildings 43 (4), 971-79. DOI: $10.1016 /$ j.enbuild.2010.12.022

Rengifo, C., Torres, E., Anaya, J., Rocha, D., Machado, M., and Navas de la Cruz, O. (2021). Aplicativo de Realidad Virtual Inmersiva Para El Aprendizaje de La Composición Volumétrica En El Diseño. Arquitectónico. Architecture, City and Environment.DOI: 10.5821/ace.16.46.9633

Meenar, M., Afzalan, N., and Hajrasouliha, A. (2019). Analyzing Lynch's City Imageability in the Digital Age. Journal of Planning Education and Research. DOI: 10.1177/0739456X19844573

Namdarian, A. Khani, S., Shieh, E., Martí, M. (2021). Redefining Urban Landscape regarding Scientific Realism Philosophy of Science. ACE: Architecture, City and Environment, 16(46), 9202. DOI: 10.5821/ace.16.46.9202

Poplin, A. (2011). Games and Serious Games in Urban Planning: Study Cases. In International Conference on Computational Science and Its Applications, 1-14. Springer. DOI: 10.1007/978-3-64221887-3

Poplin, A. (2012). Playful Public Participation in Urban Planning: A Case Study for Online Serious Games. Computers, Environment and Urban Systems 36 (3): 195-206. DOI: $\underline{10.1016 / \text { j.compenvurbsys.2011.10.003 }}$

Ratcliffe, J., and Simons, A. (2017). How Can 3D Game Engines Create Photo-Realistic Interactive Architectural Visualizations? In International Conference on Technologies for E-Learning and Digital Entertainment, 164-72. Springer. DOl: 10.1007/978-3-319-65849-0 17

Reinart, B., and Poplin, A. (2014). Games in Urban Planning-a Comparative Study. Real Corp, 1-10. https://repository.corp.at/296/ 
Rosmani, Arifah Fasha, Umi Hanim Mazlan, Siti Zulaiha Ahmad, and Adlil Ammal Mohd Kharul Apendi. (2014). Developing an Architectural Visualization Using 3D for Photo Tourism. In International Conference on Computer, Communications, and Control Technology (I4CT), 429-33. IEEE. DOI: 10.1109/I4CT.2014.6914220

Sameh, H M M. (2011). Public Participation in Urban Development Process through Information and Communication Technologies. Unpublished Master Thesis in Urban Planning, Ain Shams University, Cairo, Egypt. http://research.asu.edu.eg/handle/12345678/24292

Sanoff, H. (1999). Community Participation Methods in Design and Planning. John Wiley \& Sons. ISBN: 978-0-471-35545-8

Van Leeuwen, J., Hermans, K., Jylhä, A., Jan Quanjer, A., and Nijman, H. (2018). Effectiveness of Virtual Reality in Participatory Urban Planning: A Case Study. In Proceedings of the 4th Media Architecture Biennale Conference, 128-36. ACM. DOI: $10.1145 / 3284389.3284491$

Van Leeuwen, J., Hermans, K., Jan Quanjer, A., Jylhä, A., and Nijman, H. (2018). Using Virtual Reality to Increase Civic Participation in Designing Public Spaces. In Proceedings of the 16th International Conference on World Wide Web (ECDG'18), 230-39. ISSN: 20491034

Voigt, A., Achleitner, E., Linzer, H., Schmidinger, E., and Walchhofer, H. (2003). Multi-Dimensional Digital City Models. In Education and research in Computer Aided Architectural Design in Europe. DOI: 10.1016/S0169-2046(00)00063-3

Williams, S. (2016). Data Visualizations Break Down Knowledge Barriers in Public Engagement. The MIT Press, Cambridge, MA.

Wu, Huayi, Zhengwei He, and Jianya Gong. (2010). A Virtual Globe-Based 3D Visualization and Interactive Framework for Public Participation in Urban Planning Processes. Computers, Environment and Urban Systems 34 (4): 291-98. DOI: 10.1016/j.compenvurbsys.2009.12.001

Zhang, Yuanyi, Zhenjiang Shen, and Shuhu Liu. (2020). Virtual Reality with the Integrated Automatic Presentation Scrip for Improving Concepts Understanding of Urban Design-a Case Study in Tatsumi Region of Tokyo Bay Zone, Japan. Multimedia Tools and Applications, 79, 3125-3144. DOI: $10.1007 / \mathrm{s} 11042-018-6588-\mathrm{y}$ 